\title{
RESSUSCITAÇÃO CARDIOPULMONAR (RCP) EM PACIENTES COM COVID- 19 DURANTE O PERIOPERATÓRIO
}

Vinicius Fernando da $\mathrm{Luz}^{1}$, Wallace Andrino Silva ${ }^{2}$

1. Anestesiologista da Maternidade Escola Januário Cicco/UFRN. Doutorado pela FMUSP, MBA em gestão em Saúde pela FGV, Instrutor de ACLS American Heart Association.

2. Anestesiologista do Hospital Universitário Onofre Lopes/UFRN. Doutorado pela FMUSP, Título Superior de Anestesiologia SBA, Instrutor de ACLS American Heart Association.

Artigo produzido na Divisão de Anestesiologia do Hospital Universitário Onofre Lopes (UFRN).

Suporte financeiro: Não.

Conflito de interesse: Não.

Address for correspondence: Hospital Universitário Onofre Lopes, Divisão de Anestesiologia. Av. Nilo Peçanha, 620, 3 subsolo, Petrópolis, Natal/RN CEP:59012-300. Submetido: ago 04; aceito após revisão: nov 25, 2020.

\begin{abstract}
The incidence of symptomatic patients diagnosed with COVID-19 who require hospitalization has been increased. Among these, there are patients who need to undergo surgical procedures. Anesthetic-surgical stress increases morbidity and the risk of adverse events, which can culminate in the Cardiorespiratory Arrest event. During the cardiopulmonary resuscitation (CPR), direct contact with the patient, chest compression, positive pressure manual ventilation and advanced airway management involve exposure of professionals to large amounts of aerosols and secretions. Furthermore, viral particles can remain suspended in the air of the operating room for up to three hours. Thus, monitoring of potentially serious patients, prevention and specific CPR protocols for patients with COVID-19 are important in the perioperative context.
\end{abstract}

Key words: Cardiopulmonary resuscitation. COVID-19. Surgery. Anesthesia.

\section{RESUMO:}

Tem sido observada elevada incidência de pacientes sintomáticos com diagnóstico de COVID-19 que necessitam de internamento hospitalar. Dentre esses, encontra-se pacientes que precisam ser submetidos a procedimentos cirúrgicos. O estresse anestésico-cirúrgico aumenta morbidade e o risco de eventos adversos, podendo culminar com o evento de Parada Cardiorrespiratória (PCR). Durante o protocolo de atendimento à PCR, o contato direto com o paciente, as manobras de compressão 
Ressuscitação cardiopulmonar (RCP) em pacientes com COVID-19 durante o perioperatório Luz VF; Silva WA

torácica, ventilações manuais com pressão positiva e o manejo para obtenção de via aérea avançada envolvem a exposição dos profissionais a grandes quantidades de aerossóis e secreções. Além disso, partículas virais podem permanecerem suspensas no ar da sala operatória por até três horas. Dessa forma, monitorização do paciente potencialmente grave, prevenção e protocolos específicos de RCP para o paciente com COVID-19 são importantes no contexto perioperatório.

Palavras-chave: Ressuscitação cardiopulmonar. COVID-19. Cirurgia. Anestesia.

\section{INTRODUÇÃO}

A ressuscitação cardiopulmonar, nos últimos anos, tem apresentado melhoria significativa da taxa de sobrevivência dos pacientes após parada cardiorrespiratória $(\mathrm{RCP})^{1}$. Este sucesso ocorreu devido a grandes esforços de disseminação do treinamento, formação de equipes de resposta rápida, uso disseminado de protocolos, aumento da qualidade das compressões torácicas e da desfibrilação. Contudo, uma nova realidade imposta pela pandemia do SARS-CoV2 tem gerado novos desafios aos anestesiologistas nos casos de parada cardiopulmonar (PCR). Sobretudo, neste momento, se faz necessário garantir, além da adequada assistência ao paciente, a segurança da equipe de RCP, a fim de evitar contaminação dos profissionais envolvidos.

Tem sido observada elevada incidência de pacientes sintomáticos com diagnóstico de COVID-19 que necessitam de internamento hospitalar. De forma global, estima-se que 12 a $19 \%$ dos pacientes necessitem serem internados. Destes, um percentual de 3 a $6 \%$ seja de pacientes graves e de elevado risco ${ }^{2,3}$. Contudo, tais números podem variar de região para região. Na China, por exemplo, entre os casos confirmados, $18,5 \%$ foram considerados severos e $25,3 \%$ necessitavam de terapia intensiva. Nos EUA, em Nova lorque, o índice de hospitalização atingiu 48,7\% dos pacientes, com $10,7 \%$ dos casos necessitando de ventilação mecânica ${ }^{4}$. No Brasil, em 30/06/2020, havia 1.369.195 casos confirmados de COVID-19, com registro de 58.314 óbitos acumulados, gerando uma letalidade de 4,3\% (https://covid.saude.gov.br/). Estes números podem ainda estar subestimados, uma vez que há dificuldade de realização de testes diagnósticos em larga escala para a população brasileira ${ }^{5}$.

A pandemia de SARS-CoV2, modificou a rotina anestésica no mundo. O grande número de pacientes com COVID-19, juntamente com a lotação dos leitos hospitalares e de UTIs, além do aumento do risco cirúrgico em pacientes com COVID-19 submetidos a cirurgias, promoveram a suspensão de cirurgias eletivas pelos sistemas de saúde ${ }^{6-8}$. Este ponto expos ainda mais o profissional anestesiologista a atuar em cirurgias de emergência, com pacientes graves, ou mesmo em outros cenários como em UTIs, prontos-socorros e equipes de resposta rápida à via aérea, a depender da necessidade regional ${ }^{9}$.

Nesse contexto, com o aumento do número de casos e de óbitos por COVID-19, os protocolos de RCP se tornaram ainda mais importantes. Contudo, também aumentaram os riscos. As manobras de RCP geram grande quantidade de aerossóis e 
Ressuscitação cardiopulmonar (RCP) em pacientes com COVID-19 durante o perioperatório Luz VF; Silva WA

aumentam a chance de contaminação das equipes de assistência. Durante o protocolo de atendimento à PCR, o contato direto com o paciente, as manobras de compressão torácica, ventilações manuais com pressão positiva e o manejo para obtenção de via aérea avançada envolvem a exposição dos profissionais a grandes quantidades de aerossóis e secreções ${ }^{10}$. Ainda, partículas virais podem permanecerem suspensas no ar da sala operatória por até 03 horas $^{11}$. O SARS-CoV2 pode ser detectado em algumas superfícies por até 72 horas após a contaminação ${ }^{11}$.

Dessa forma, antes de iniciar a RCP, torna-se obrigatório o uso de equipamentos de proteção individual por todos os integrantes da equipe. Máscara N95, face shield, avental impermeável, luvas e propés devem estar disponíveis ${ }^{12,13}$. Não se deve expor qualquer integrante da equipe a riscos de contaminação ${ }^{14}$.

\section{PCR NA COVID-19}

O SARS-CoV2 pode promover sepse e síndrome do desconforto respiratório agudo (SDRA) com quadros respiratórios graves - dispneia, frequência respiratória $\geq$ $30 /$ min, saturação de $\mathrm{O}_{2}$ no sangue $\leq 93 \%$, relação $\mathrm{PaO}_{2} / \mathrm{FiO}_{2}<300$ e/ou pulmão com infiltrado ocupando mais de $50 \%$ do parênquima pulmonar ${ }^{15}$. O paciente pode evoluir para insuficiência respiratória, choque séptico, acidose, hipóxia refratária e de difícil tratamento, PCR e óbito ${ }^{16-18}$. Dessa forma, uma das principais causas de PCR em pacientes com COVID-19 é o quadro de hipóxia.

Tem sido observado que as formas mais graves de apresentação clínica do COVID-19 e maior mortalidade estão relacionadas aos pacientes com comorbidades e idosos, principalmente a partir de 65 anos $^{2}$. Pacientes com doenças que são predisponentes ao infarto agudo do miocárdio (IAM) como obesidade, hipertensão arterial sistêmica, diabetes mellitus, cardiopatias e doenças vasculares apresentam também desfechos menos favoráveis ao serem infectados pelo SARS-CoV2,10. Sabe-se que o próprio vírus está relacionado à coagulopatia e aos fenômenos tromboembólicos, favorecendo eventos cardíacos e neurológicos isquêmicos, como o IAM e AVC ${ }^{19-22}$. Dessa forma, o COVID-19 atua como um fator de risco independente para IAM ${ }^{23}$. Outras possíveis complicações cardíacas incluem insuficiência cardíaca aguda, arritmias e choque cardiogênico ${ }^{24,25}$.

Outra possibilidade de PCR em pacientes com COVID-19 ocorre por aumento do intervalo QT relacionado ao uso de hidroxicloroquina e azitromicina ${ }^{26}$. Este efeito pode promover arritmias ventriculares e Torsade de Pointes ${ }^{27}$. Em anestesia, deve-se lembrar da possível associação, durante os procedimentos, com outros fármacos que também podem promover o mesmo efeito de prolongamento do intervalo QT, como a ondasetrona, amiodarona, levofloxacina e escitalopram. O paciente já pode estar fazendo uso de tais medicações. Ainda, o paciente pode apresentar condições clínicas que favoreçam o prolongamento do intervalo QT, como hipocalemia, hipomagnesemia e hipocalcemia, bem com doenças cardíacas estruturais ${ }^{28}$.

Dentre os quadros clínicos gerais de PCR e óbito nos pacientes com COVID-19 estão ${ }^{29}$ : 
1. Falência múltipla de órgãos: mais comum em idosos com múltiplas comorbidades, evoluindo para insuficiência respiratória, insuficiência renal e colapso hemodinâmico do paciente.

2. Parada cardíaca súbita: apesar do paciente apresentar relativa estabilidade do quadro clínico, evolui para parada cardíaca súbita e óbito.

3. Exacerbação súbita da condição basal: quadro de piora exacerbada e de rápida progressão, a partir de uma condição estável, evoluindo com disfunção respiratória grave, insuficiência cardíaca, choque, parada cardíaca e óbito.

Em casos de PCR nos pacientes com COVID-19, além de considerar as causas mais comuns como hipóxia, trombose coronária e acidose, deve-se observar o caso clínico. É importante ponderar todos os $5 \mathrm{Hs}$ (hipóxia, acidose, hiper/hipocalemia, hipovolemia e hipotermia) e 5Ts (trombose coronariana, tamponamento cardíaco, trombose pulmonar, pneumotórax hipertensivo e toxinas).

Para anestesia, é importante ponderar adicionalmente mais 3Hs (hipoglicemia, reflexo hipervagal e hipertermia maligna) e 3Ts (trauma, hipertensão pulmonar e prolongamento do QT). Ainda deve-se observar a possibilidade de sobredose de anestésicos venosos e/ou inalatórios, intoxicação por anestésicos locais, bloqueio de neuroeixo alto com bloqueio simpático, choque anafilático, choque hemorrágico cirúrgico, reação transfusional, auto-PEEP, broncoespasmo, embolia gasosa, embolia amniótica, administração errada de fármacos, distúrbios hidroeletrolíticos, falha de marca-passo e outras possíveis relações ${ }^{30}$.

\section{Monitorização, prevenção e políticas hospitalares para PCR na COVID-19}

A monitorização e detecção precoce dos pacientes graves com COVID-19 e de maior risco para PCR tem grande importância no ambiente hospitalar ${ }^{31}$. Permite à equipe de PCR ter mais tempo, a fim de preparar materiais e equipamentos para um possível início do protocolo de RCP, realizar antecipadamente a divisão de funções da equipe, revisar o caso clínico, alertar o time de resposta rápida, se houver, reduz o estresse envolvido e permite haver tempo hábil para paramentação adequada com os EPIs.

Em relação ao ambiente de atendimento, se possível, deve-se transportar o paciente para local adequado e isolado. Se disponível no hospital, é recomendado o uso de salas com pressão de ar negativa, a fim de reduzir a exposição da equipe de RCP. É indicado também fechar portas e aberturas que contaminem ambientes adjacentes ao local de atendimento, de modo a reduzir a chance contaminação de salas contíguas, ou mesmo de outros pacientes próximos ${ }^{10,31,32}$.

A vigilância dos pacientes graves também favorece a prevenção de casos de intubação emergencial. Pode haver dificuldade de organização da equipe, atraso na assistência do paciente pela necessidade de paramentação e proteção, preparo inadequado dos equipamentos e fármacos, estresse e redução da chance de sucesso para obtenção de via avançada ${ }^{10}$. 
Ressuscitação cardiopulmonar (RCP) em pacientes com COVID-19 durante o perioperatório Luz VF; Silva WA

Em alguns casos, de acordo com os protocolos institucionais locais, deve-se ponderar em equipe sobre conflitos éticos de realizar ou não a RCP ${ }^{33}$. Pode haver escassez de EPIs, sobrecarga do sistema de saúde com limitação de recursos humanos, falta de equipamentos, medicações e leitos hospitalares ${ }^{34}$. Alguns pacientes podem ter prognóstico reservado e há elevado risco de contaminação das equipes durante as manobras de ressuscitação, sendo necessário ponderar o início de RCP de acordo com a situação clínica de cada paciente dentro do contexto de cada instituição ${ }^{34,35}$. Dessa forma, os casos devem ser analisados em equipe, terem registro devido no prontuário da conduta a ser adotada e a família participar desse processo, devendo ser informada da situação do paciente ${ }^{36}$.

As instituições devem promover treinamento e criar políticas específicas, escores de gravidade, fluxograma de ação e protocolos para pacientes com COVID-19 em suas unidades, recomendando padrões de início e término dos protocolos de RCP nesses pacientes ${ }^{10,34}$. Tais documentos deverão considerar os fatores de risco do paciente, limitações locais, status das equipes, possibilidade de encaminhamento e transporte, além da probabilidade de sobrevivência. Sistemas de estratificação de risco e políticas hospitalares implementadas devem ser comunicadas aos pacientes e seus familiares $^{10,32,36}$.

\section{RCP NA COVID-19}

Com dito anteriormente, no contexto de pacientes com suspeita, ou diagnóstico de COVID-19, é obrigatório e prioritário o uso de EPIs antes de se iniciar o protocolo de $\mathrm{RCP}^{10,31}$. Além da segurança individual, se faz necessário preservar a capacidade de atendimento das unidades cirúrgicas e equipes hospitalares. Os estudos têm demonstrado que os profissionais de saúde envolvidos diretamente na assistência a pacientes com COVID-19 apresentam risco aumentado de contrair a doença ${ }^{37-39}$. Dessa forma, deve-se reduzir o número de profissionais envolvidos na RCP. Se disponível, para as manobras de compressão torácica, utilize dispositivos mecânicos automáticos, como intuito de reduzir o número profissionais durante a $\mathrm{RCP} \mathrm{P}^{10,40}$. Novos profissionais que entrem no local de assistência durante a RCP devem ser informados sobre o risco de COVID-19 e estarem devidamente paramentados.

Ao iniciar as manobras de compressão torácica, caso o paciente não esteja com via aérea avançada, deve-se considerar colocar a máscara facial sobre a boca e nariz do mesmo. Esta conduta pode reduzir a disseminação do vírus ao ambiente durante a $\mathrm{RCP}{ }^{41}$.

Assim que possível e de maneira precoce, deve-se garantir a obtenção de uma via aérea avançada, havendo preferência por se realizar intubação orotraqueal com tubo com balonete. O intuito é reduzir a formação de aerossóis e fornecer melhor qualidade da ventilação e oxigenação. As compressões devem ser interrompidas para realizar o procedimento. É recomendado uso de videolaringoscópio, se houver profissional já experiente com a técnica, uso de fio guia, êmbolo de proteção na saída do tubo e disponibilidade de uma pinça kelly-forte para ocluir o tubo orotraqueal 
Ressuscitação cardiopulmonar (RCP) em pacientes com COVID-19 durante o perioperatório Luz VF; Silva WA

durante a conexão com o ventilador mecânico. A checagem do posicionamento correto do tubo deve ser feita por meio de capnografia e pela visualização da expansibilidade torácica simétrica, evitando-se a ausculta pulmonar. Para realização do procedimento, deve-se dar preferência ao médico mais experiente no manejo via aérea avançada ${ }^{42,43}$.

É obrigatório o acoplamento de um filtro HEPA após o tubo orotraqueal e ao ramo expiratório do circuito ventilatório. O filtro HEPA (High Efficiency Particulate Arrestance - alta eficiência na separação de partículas) deve ser acoplado tanto ao dispositivo balão-válvula-máscara, quanto ao sistema de ventilação mecânica. Uma possível configuração alternativa é o uso de um filtro HME após o tubo orotraqueal na escassez de filtros HEPA, mas pelo menos mantendo-se o ramo expiratório com o filtro de alta eficiência HEPA.

Em caso de falha da intubação, mantenha a RCP com a relação 30 compressões para 2 ventilações manuais com dispositivo balão-válvula-máscara, ou o aparelho de anestesia, tendo sempre um filtro HEPA acoplado. A ventilação deve ser realizada com máscara bem justa ao rosto do paciente, podendo ser realizada a 4 mãos com ajuda de outro profissional. É recomendado o uso de cânula naso ou orofaríngea de tamanho adequado para manter a via aérea patente às ventilações manuais.

Durante a RCP, em caso de dificuldade de intubação, ou de ventilação, considere o uso de dispositivos supraglóticos, como a máscara laríngea ${ }^{42,44}$. Mantenha a relação 30:2, reduzindo a o formação de aerossóis e evitando vazamentos entre o dispositivo e a laringe ${ }^{45}$. Deve-se dar preferência a dispositivos de alta qualidade, atentando-se para ausência de escapes durante a ventilação, minimizando a liberação de aerossóis. Os dispositivos devem possibilitar passagem de sonda para aspiração de conteúdo gástrico, se o paciente estiver com estômago cheio, uma vez que os dispositivos supra-glóticos não garantem proteção adequada contra broncoaspiração. As manobras de RCP podem aumentar a pressão intra-gástrica, favorecendo o retorno do conteúdo alimentar ainda presente no estômago.

Após a intubação, devido os movimentos bruscos de RCP, pode haver desconexão do sistema ventilatório. É recomendado checar as conexões, fixar possíveis pontos de desconexão e verificar a fixação do tubo orotraqueal. Deve-se realizar o acoplamento da capnografia para avaliar a qualidade das manobras de RCP. Uma ETCO $>10 \mathrm{mmHg}$ indica que eficácia das manobras, bem como permite observar o retorno da circulação espontânea (RCE). De forma alternativa, caso o paciente já esteja com monitorização de pressão arterial invasiva, uma pressão arterial diastólica $>20 \mathrm{mmHg}$ também indica eficácia das manobras de RCP ${ }^{46-48}$.

Minimize as desconexões do circuito durante a RCP. Caso seja necessário, antes de desconectar, pare a ventilação, realize o clampleamento do tubo, mantenha o filtro HEPA no circuito do ventilador mecânico.

O ventilador mecânico deve ser ajustado e mantido durante a RCP da seguinte forma ${ }^{10,31}$ : 
- Ventilação assíncrona com as compressões torácicas.

- Ajustar a frequência respiratória para 10 irpm e 30 irpm para crianças.

- Configurar $\mathrm{FiO}_{2}$ em $100 \%$.

- Selecionar modo de pressão assisto-controlada e limitar a pressão para gerar apenas o volume adequado $(6 \mathrm{ml} / \mathrm{Kg}$ de peso ideal e de 4$6 \mathrm{ml} / \mathrm{Kg}$ para neonatos).

- Desativar a sensibilidade (trigger) do ventilador, evitando a ativação de ciclos ventilatórios devido às manobras de compressão torácica e prevenindo hiperventilação.

- Zerar o PEEP.

- Desligar alarmes.

- Checar e reforçar conexões do sistema ventilatório para evitar desconexões durante as manobras de RCP.

Até o momento, não há dados suficientes para recomendações do uso de ECMO em casos de PCR nos pacientes com COVID-19.

Durante a RCP, é importante que as equipes estabeleçam um sistema de comunicação eficiente e em alça fechada. Os EPIs e o momento de RCP podem dificultar a atenção aos comandos e reconhecimento dos profissionais no ambiente de emergência. Se possível, conheça as capacidades de cada membro do seu time antecipadamente e identifique os externamente sobre os EPIs.

Com base nos protocolos de suporte de vida avançado em cardiologia (ACLS advanced cardiac life support) e nas propostas de modificações para os pacientes em PCR com suspeita, ou diagnóstico de COVID-19, este artigo sugere novos fluxogramas para atendimento (figuras 1 e 2).

\section{Pacientes pronados}

Para os pacientes pronados sem via aérea avançada, considere supinar o paciente para iniciar o protocolo de RCP e obter maior sucesso no manejo da via aérea.

Para pacientes pronados com via aérea avançada, de preferência inicie e mantenha a RCP nesta posição. Somente pondere retornar o paciente à posição supina se existirem profissionais suficientes, não houver riscos de desconexões, extubação e grande contaminação do ambiente com secreções e aerossóis ${ }^{49}$.

- Posicione pás adesivas de desfibrilação em situação anteroposterior entre o ápice cardíaco/ linha axilar média esquerda e a região escapular direita. De forma alternativa, pode-se posicionar as pás de maneira bi-axilar ${ }^{45}$.

- O posicionamento das mãos para RCP deve estar na altura vertebral de $\mathrm{T} 7 / 10^{50}$.

\section{Retorno da Circulação Espontânea e protocolo pós-parada}


Ressuscitação cardiopulmonar (RCP) em pacientes com COVID-19 durante o perioperatório Luz VF; Silva WA

Havendo retorno da circulação espontânea, deve-se seguir o mesmo protocolo recomendado pelo ACLS, revendo os sinais vitais e buscando estabilização do paciente. ${ }^{46}$ Ao realizar a regulação do caso para a UTI, ou hemodinâmica, deve-se informar sobre suspeita, ou diagnóstico de COVID-19 ao setor ao qual o paciente será enviado.

Ao final, os profissionais envolvidos na RCP devem realizar desparamentação adequada, evitando-se contaminarem neste momento. ${ }^{45}$ Se possível, devem ser auxiliados, em local apropriado com indicativos lembrando o processo seguro de retirada dos EPIs. Devem ainda realizarem a higienização das mãos com água e sabão e usar álcool gel ou a $70 \%{ }^{51}$.

Os equipamentos utilizados na RCP devem ser descartados, ou separados adequadamente para limpeza e esterilização. Da mesma forma, deve haver limpeza cuidadosa do local e das superfícies.

O debriefing com a equipe deve ser realizado, com o objetivo de melhorar a eficiência das equipes e fornecer ajuda psicológica para os próprios profissionais de saúde superarem o evento ${ }^{52}$.

\section{CONSIDERAÇÕES FINAIS}

O profissional anestesiologista, no contexto PCR de paciente com suspeita, ou diagnóstico de COVID-19, deve ter capacidade de alinhar conhecimentos do protocolo de ACLS, com possíveis complicações cirúrgicas e anestésicas, avaliando a cada situação. De forma paralela e tão importante quanto, é necessário a organização das instituições com protocolos e treinamento das equipes, com o objetivo de garantir a efetividade dentre os vários cenários possíveis e complexidade de atendimento envolvida nos pacientes com COVID-19. 


\section{PRINCIPAIS DESTAQUES DA RCP NO PACIENTE COM COVID-19}

\section{Causas de PCR na COVID-19}
1. Hipóxia.
2. Acidose.
3. Trombose coronariana.
4. Causas cirúrgico-anestésicas.
5. $8 \mathrm{Hs}$ e $8 \mathrm{Ts}$.

\section{Ambiente de atendimento, ética e políticas institucionais}

1. Monitorização precoce dos casos graves.

2. Usar sala com pressão negativa, se possível.

3. Usar local isolado, fechar portas e aberturas, evitando contaminação contígua.

4. Desenvolver e implementar protocolos institucionais locais e escores de gravidade para COVID-19.

5. Registrar e informar caso e condutas aos profissionais e familiares.

6. Realizar treinamentos de atendimento à PCR no COVID-19.

\section{Redução da exposição dos profissionais}

1. Uso obrigatório de EPIs por toda equipe.

2. Limitar número de profissionais na sala.

3. Comunicar risco de COVID-19 a novos profissionais adentrando na cena.

4. Considerar uso de dispositivos mecânicos automáticos de RCP.

\section{Estratégias de redução de risco de aerossóis, via aérea, oxigenação e}

1. Uso de filtro HEPA para dispositivo balão-válvula-máscara e circuito ventilatório do aparelho de anestesia.

2. Intubação precoce com tubo com balonete e manter sob ventilação mecânica.

3. Parar compressões para intubação.

4. Considere uso de videolaringoscópio.

5. Clampear tubo com pinça Kelly-forte e uso de fio guia com êmbolo.

6. Acoplar capnografia.

7. Em caso de falha, considere dispositivo supra-glótico com a máscara laríngea.

8. Evite possíveis desconexões e minimize o intervalo das mesmas.

9. Configurar ventilador mecânico para RCP e manter ventilação assíncrona com as manobras. 
Ressuscitação cardiopulmonar (RCP) em pacientes com COVID-19 durante o perioperatório Luz VF; Silva WA

\section{PRINCIPAIS DESTAQUES DA RCP NO PACIENTE COM COVID-19}

\section{RCP na COVID-19}

1. Manter protocolo de ACLS.

2. Otimizar comunicação entre os profissionais (alça fechada e identificação).

3. Em pacientes pronados e intubados, não mudar posição e realizar RCP em prona.

\section{Retorno da circulação espontânea}

1. Checar sinais vitais e manter estabilidade do paciente.

2. Solicitar exames.

3. Ao regular caso para UTI, ou hemodinâmica, informar sobre risco de COVID-19. 


\section{BLS COVID-19 Algoritmo}

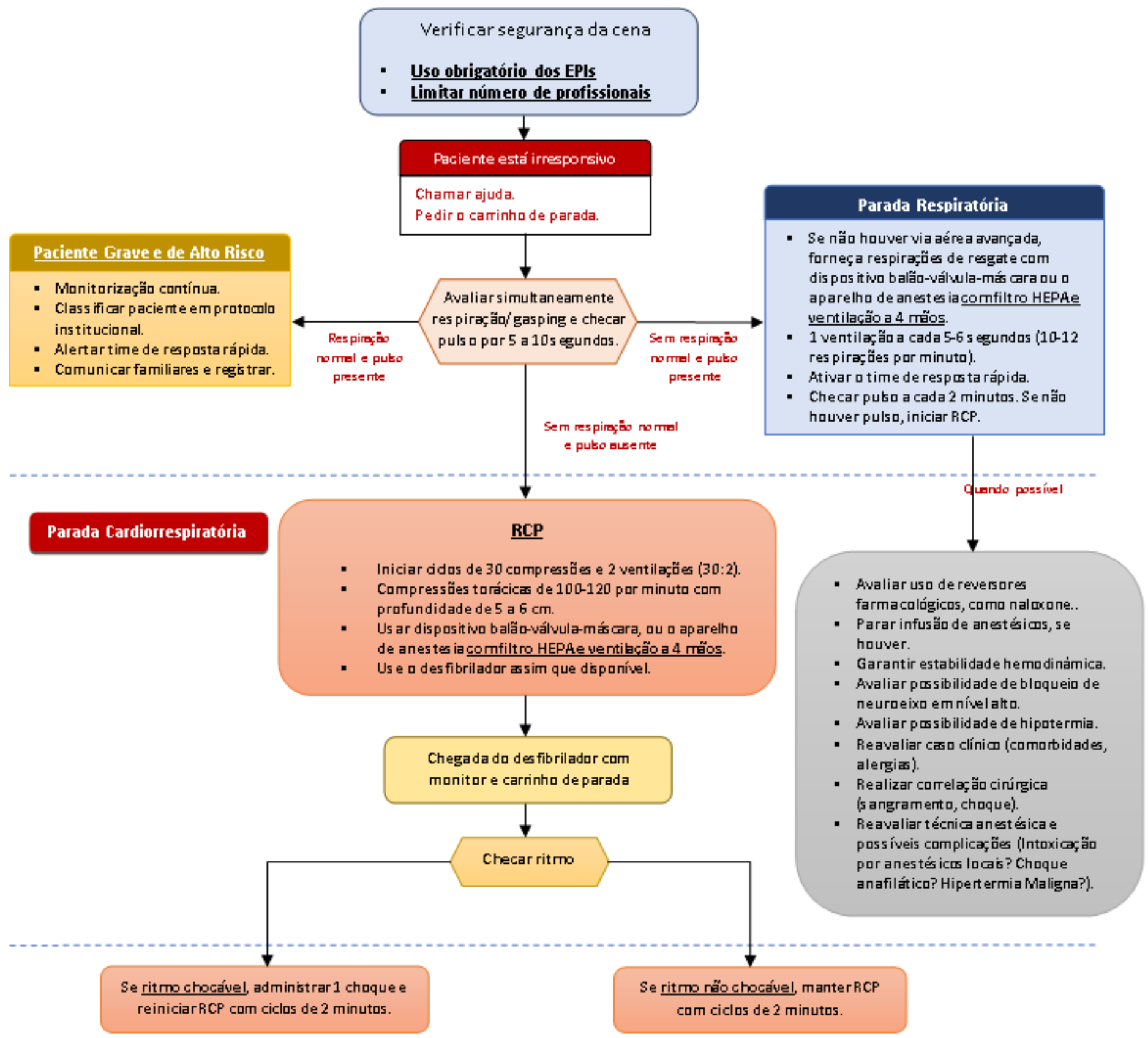

\section{ACLS}




\section{ACLS COVID-19 Algoritmo}

\section{Uso obrigatório dos EPIs}

- Limitar número de profissionais.

- Ponderar a ressuscitacão cardiopulmonar de acordo com os protocolos locais e estratificacão do paciente.

$$
\text { Nล้อ } \downarrow
$$

\section{Iniciar RCP}

- Fornecer oxigênio a 100\% (limitar aerossóis).

- Conectar monitorizacão ao desfibrilador.

- Preparar material para intubacão (com capnografia).

FV/ TV sem pulso

\section{Priorizar intubação e reiniciar RCP}

- Pausar compressões para intubação

- Sefalha ou atraso para intubação, considerar uso de máscara laríngea.

- Conectar ventilador com filtro, se possível

- Configurar ventilador adequadamente, checar e reforcar conexões da ventilacão.

- Se disponíyel, considerar uso de dispositivo mecânico automático de RCP.
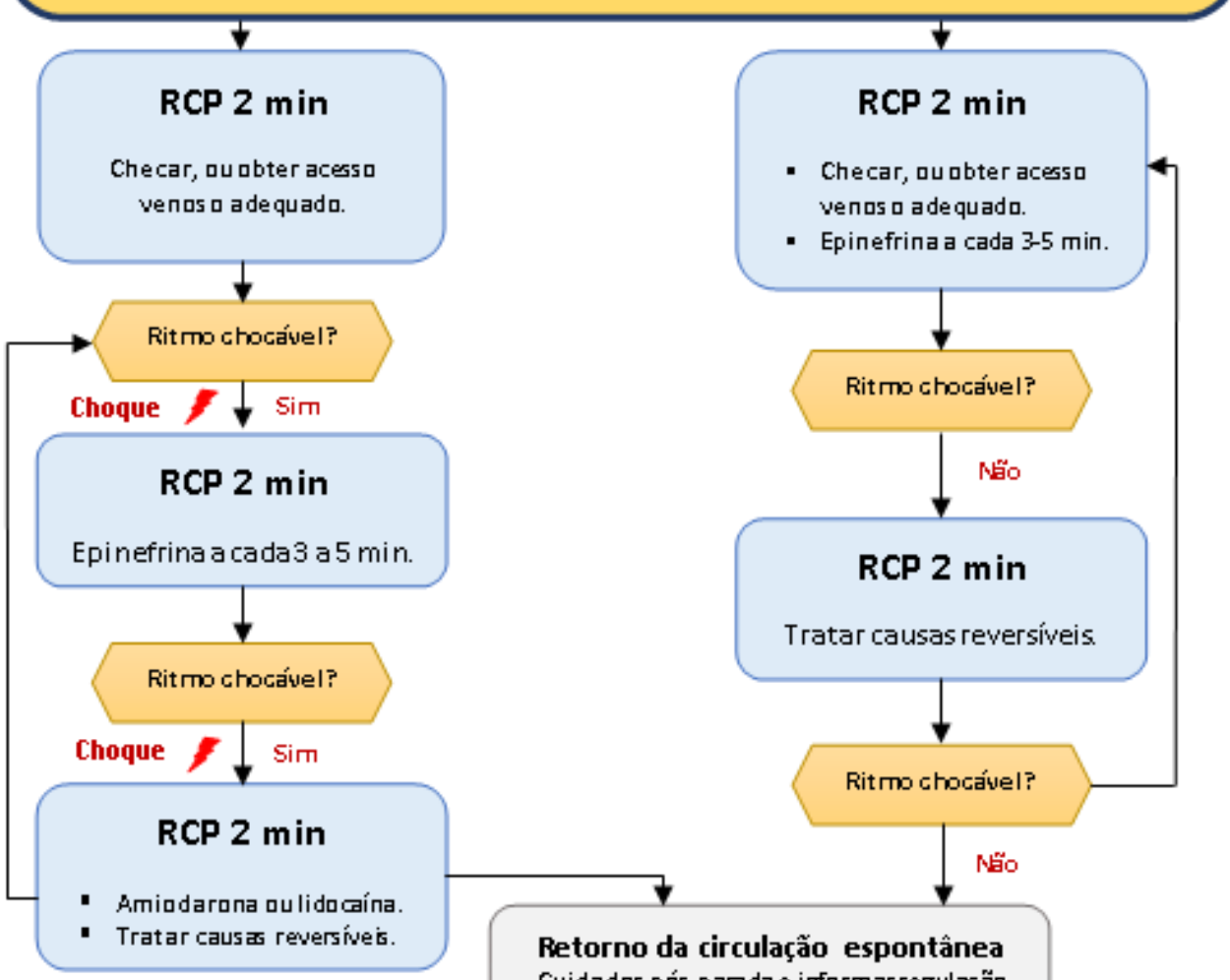

RCP 2 min

- Checar, au abter acess venas a adequada.

- Epinefrina a cada 3-5 min

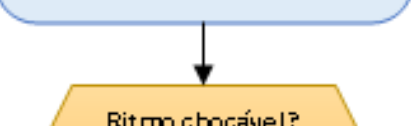

Ritmo chocável? Nต้อ

\section{RCP 2 min}

Tratar causas reversiveis.

Retorno da circulação espontânea

Cuidadas pós-parada e infarmar regulaçäa s abre risca de COVID-19.

\section{Qualidade da RCP}

- 100 a 120 campressães par minut

- 5 a $6 \mathrm{~cm}$ de prafundidade.

- Minimizarintertupçães.

- Evitar ventilaçãa excessiva.

- Revezar campressores a cada 2 minutas ou a

- Se nãa hquver via aérea avançada, realizar 30:2, relaçãa campressä̃-ventilaçä̃a.

- Capnografia: PETC02 > 10 mmH indica efetividade da manabra de RCP.

- Press ãa arterial invasiva: pressãa diøtálica > $20 \mathrm{mmHg}$ indica efet ividade da manab ra de RCP.

\section{Via aérea ayancada}

- Realizar imtub açãutãa logos eja possível. - Cansidere usa de videnlaringas ápin. - Em cas a de falha de intubaçäa, au dificuldade de vemtilaçãa, cansidere $a$ us a de dis pos itiva supraglátio, camb a mós cara laríngea.

- Us ar capnografía e expars ibilidade torácica para canfirmar intub açãa.

- Ventilar de farma đs sín campress ães cantínuส, 1 ventil a̧̧ãa a cada 6 $s$ egundas (10 irpm).

\section{Fármacos na RCP}

- Epinefrinalv $1 \mathrm{mg}$ a cada 3 a 5 minutas. - AmiadaranalY: Primeira dase $300 \mathrm{mg}$ em bálus . Segunda dw e 150 mg em bálus OU

- Lidacaínaly: Primeira dose 1-1,5 mg/Kg. Segunda dase 0,5 a 0,75 mg/Kg.

\section{Causas reversiveis (8Hs e $8 \mathrm{Ts}$ )}

- Hipóxia

- Hipavalemia

- $\mathrm{H}+$ (acidas e)

- Hipatermia

- Hipo/Hipercalemia

- Hip oglicemia

- Hipertemia maligna

- Hipervagal, reflexם

- Toxinas

- Tampanamenta Cardíaca

- Trambos e caranariana

- Trambas e pulmanar

- Preumatárax hipertersiva

- Trauma

- Pralangamenta de QT

- Hipertensãa pulmanar

\section{Após a RCP}

- Retirada cuidadma dø EPIs.

- Lavagem da mãas.

- Des carte de equipamentas e limpeza da

lacal.

- Debriefing.

- Regis tra e infarmar familiarer. 
Ressuscitação cardiopulmonar (RCP) em pacientes com COVID-19 durante o perioperatório Luz VF; Silva WA

\section{REFERÊNCIAS}

1. Virani SS, Alonso A, Benjamin EJ, et al. Heart Disease and Stroke Statistics-2020 Update: A Report From the American Heart Association. Circulation. 2020;141(9):e139-e596.

2. Team CC-R. Severe Outcomes Among Patients with Coronavirus Disease 2019 (COVID-19) - United States, February 12-March 16, 2020. MMWR Morb Mortal Wkly Rep. 2020;69(12):343-346.

3. Wu Z, McGoogan JM. Characteristics of and Important Lessons From the Coronavirus Disease 2019 (COVID-19) Outbreak in China: Summary of a Report of 72314 Cases From the Chinese Center for Disease Control and Prevention. JAMA. 2020.

4. Petrilli CM, Jones SA, Yang J, et al. Factors associated with hospitalization and critical illness among 4,103 patients with COVID-19 disease in New York City. 2020:2020.2004.2008.20057794.

5. Diaz-Quijano FA, Silva JMNd, Ganem F, Oliveira S, Vesga-Varela AL, Croda J. A model to predict SARS-CoV-2 infection based on the first three-month surveillance data in Brazil. 2020:2020.2004.2005.20047944.

6. Miller TR, Radcliff TA. Economic Shocks From the Novel COVID-19 Pandemic for Anesthesiologists and Their Practices. Anesth Analg. 2020;131(1):112-116.

7. Haina KMK, Jr. Use of Anesthesia Machines in a Critical Care Setting During the Coronavirus Disease 2019 Pandemic. A A Pract. 2020;14(7):e01243.

8. Doglietto F, Vezzoli M, Gheza F, et al. Factors Associated With Surgical Mortality and Complications Among Patients With and Without Coronavirus Disease 2019 (COVID19) in Italy. JAMA Surg. 2020.

9. Yang $\mathrm{M}$, Dong $\mathrm{H}$, Lu Z. Role of anaesthesiologists during the COVID-19 outbreak in China. Br J Anaesth. 2020;124(6):666-669.

10. Edelson DP, Sasson C, Chan PS, et al. Interim Guidance for Basic and Advanced Life Support in Adults, Children, and Neonates With Suspected or Confirmed COVID-19: From the Emergency Cardiovascular Care Committee and Get With The GuidelinesResuscitation Adult and Pediatric Task Forces of the American Heart Association. Circulation. 2020;141(25):e933-e943.

11. van Doremalen N, Bushmaker T, Morris DH, et al. Aerosol and Surface Stability of SARS-CoV-2 as Compared with SARS-CoV-1. N EngI J Med. 2020;382(16):1564-1567.

12. Wax RS, Christian MD. Practical recommendations for critical care and anesthesiology teams caring for novel coronavirus (2019-nCoV) patients. Can J Anaesth. 2020;67(5):568-576.

13. Tang LY, Wang J. Anesthesia and COVID-19: What We Should Know and What We Should Do. Semin Cardiothorac Vasc Anesth. 2020;24(2):127-137.

14. Kramer DB, Lo B, Dickert NW. CPR in the Covid-19 Era - An Ethical Framework. N Engl J Med. 2020. 
Ressuscitação cardiopulmonar (RCP) em pacientes com COVID-19 durante o perioperatório Luz VF; Silva WA

15. Alhazzani W, Moller MH, Arabi YM, et al. Surviving Sepsis Campaign: Guidelines on the Management of Critically III Adults with Coronavirus Disease 2019 (COVID-19). Crit Care Med. 2020;48(6):e440-e469.

16. Sahu KK, Mishra AK, Martin K, Chastain I. COVID-19 and restrictive lung disease: A deadly combo to trip off the fine balance. Monaldi archives for chest disease $=$ Archivio Monaldi per le malattie del torace. 2020;90(2).

17. Cai A, McClafferty B, Benson J, et al. COVID-19: Catastrophic Cause of Acute Lung Injury. S D Med. 2020;73(6):252-260.

18. Berlin DA, Gulick RM, Martinez FJ. Severe Covid-19. N Engl J Med. 2020.

19. Tavazzi G, Civardi L, Caneva L, Mongodi S, Mojoli F. Thrombotic events in SARS-CoV2 patients: an urgent call for ultrasound screening. Intensive Care Med. 2020;46(6):1121-1123.

20. Duroi I, Van Durme F, Bruyns T, Louage S, Heyse A. Fatal Ischaemic Stroke During COVID-19 and Acute Lung Injury. Eur J Case Rep Intern Med. 2020;7(6):001732.

21. Gris JC, Perez-Martin A, Quere I, Sotto A. COVID-19 associated coagulopathy: The crowning glory of thrombo-inflammation concept. Anaesth Crit Care Pain Med. 2020.

22. Connors JM, Levy JH. COVID-19 and its implications for thrombosis and anticoagulation. Blood. 2020;135(23):2033-2040.

23. Belani $P$, Schefflein J, Kihira S, et al. COVID-19 Is an Independent Risk Factor for Acute Ischemic Stroke. AJNR Am J Neuroradiol. 2020.

24. Dhakal BP, Sweitzer NK, Indik JH, Acharya D, William P. SARS-CoV-2 Infection and Cardiovascular Disease: COVID-19 Heart. Heart, lung \& circulation. 2020.

25. Prasad A, Panhwar S, Hendel RC, et al. COVID-19 and the cardiovascular system: A review of current data, summary of best practices, outline of controversies, and illustrative case reports. American heart journal. 2020;226:174-187.

26. Saleh M, Gabriels J, Chang D, et al. Effect of Chloroquine, Hydroxychloroquine, and Azithromycin on the Corrected QT Interval in Patients With SARS-CoV-2 Infection. Circ Arrhythm Electrophysiol. 2020;13(6):e008662.

27. Ayad RF, Assar MD, Simpson L, Garner JB, Schussler JM. Causes and management of drug-induced long QT syndrome. Proc (Bayl Univ Med Cent). 2010;23(3):250-255.

28. Trinkley KE, Page RL, 2nd, Lien H, Yamanouye K, Tisdale JE. QT interval prolongation and the risk of torsades de pointes: essentials for clinicians. Curr Med Res Opin. 2013;29(12):1719-1726.

29. Song W, Liu Y, Ouyang Y, et al. Recommendations on cardiopulmonary resuscitation strategy and procedure for novel coronavirus pneumonia. Resuscitation. 2020;152:52-55.

30. Moitra VK, Gabrielli A, Maccioli GA, O'Connor MF. Anesthesia advanced circulatory life support. Can J Anaesth. 2012;59(6):586-603. 
Ressuscitação cardiopulmonar (RCP) em pacientes com COVID-19 durante o perioperatório Luz VF; Silva WA

31. Timerman S, Guimarães HP, Rodrigues RdR, et al. Recommendations for Cardiopulmonary Resuscitation (CPR) of patients with suspected or confirmed COVID-19. Rev Bras Anestesiol. 2020.

32. Cheruku S, Dave S, Goff K, et al. Cardiopulmonary Resuscitation in Intensive Care Unit Patients With Coronavirus Disease 2019. J Cardiothorac Vasc Anesth. 2020.

33. Mahase E, Kmietowicz Z. Covid-19: Doctors are told not to perform CPR on patients in cardiac arrest. BMJ. 2020;368:m1282.

34. Mahmood SU, Crimbly F, Khan S, Choudry E, Mehwish S. Strategies for Rational Use of Personal Protective Equipment (PPE) Among Healthcare Providers During the COVID-19 Crisis. Cureus. 2020;12(5):e8248.

35. Huang C, Wang Y, Li X, et al. Clinical features of patients infected with 2019 novel coronavirus in Wuhan, China. Lancet. 2020;395(10223):497-506.

36. Emanuel EJ, Persad G, Upshur R, et al. Fair Allocation of Scarce Medical Resources in the Time of Covid-19. N Engl J Med. 2020;382(21):2049-2055.

37. Kluytmans-van den Bergh MFQ, Buiting AGM, Pas SD, et al. Prevalence and Clinical Presentation of Health Care Workers With Symptoms of Coronavirus Disease 2019 in 2 Dutch Hospitals During an Early Phase of the Pandemic. JAMA Netw Open. 2020;3(5):e209673.

38. Cheng VC, Wong SC, Yuen KY. Estimating Coronavirus Disease 2019 Infection Risk in Health Care Workers. JAMA Netw Open. 2020;3(5):e209687.

39. Lai X, Wang M, Qin C, et al. Coronavirus Disease 2019 (COVID-2019) Infection Among Health Care Workers and Implications for Prevention Measures in a Tertiary Hospital in Wuhan, China. JAMA Netw Open. 2020;3(5):e209666.

40. Pollack RA, Brown SP, Rea T, et al. Impact of Bystander Automated External Defibrillator Use on Survival and Functional Outcomes in Shockable Observed Public Cardiac Arrests. Circulation. 2018;137(20):2104-2113.

41. Ott M, Milazzo A, Liebau S, et al. Exploration of strategies to reduce aerosol-spread during chest compressions: A simulation and cadaver model. Resuscitation. 2020;152:192-198.

42. Cook TM, El-Boghdadly K, McGuire B, McNarry AF, Patel A, Higgs A. Consensus guidelines for managing the airway in patients with COVID-19: Guidelines from the Difficult Airway Society, the Association of Anaesthetists the Intensive Care Society, the Faculty of Intensive Care Medicine and the Royal College of Anaesthetists. Anaesthesia. 2020;75(6):785-799.

43. Orser BA. Recommendations for Endotracheal Intubation of COVID-19 Patients. Anesth Analg. 2020;130(5):1109-1110.

44. Scapigliati A, Gulli A, Semeraro F, et al. How to ventilate during CPR in time of Covid19? Resuscitation. 2020;151:148-149.

45. Nolan JP, Monsieurs KG, Bossaert L, et al. European Resuscitation Council COVID-19 guidelines executive summary. Resuscitation. 2020;153:45-55. 
Ressuscitação cardiopulmonar (RCP) em pacientes com COVID-19 durante o perioperatório Luz VF; Silva WA

46. Link MS, Berkow LC, Kudenchuk PJ, et al. Part 7: Adult Advanced Cardiovascular Life Support: 2015 American Heart Association Guidelines Update for Cardiopulmonary Resuscitation and Emergency Cardiovascular Care. Circulation. 2015;132(18 Suppl 2):S444-464.

47. Ahrens T, Schallom L, Bettorf K, et al. End-tidal carbon dioxide measurements as a prognostic indicator of outcome in cardiac arrest. Am J Crit Care. 2001;10(6):391398.

48. Touma O, Davies $M$. The prognostic value of end tidal carbon dioxide during cardiac arrest: a systematic review. Resuscitation. 2013;84(11):1470-1479.

49. Wei J, Tung D, Sue SH, Wu SV, Chuang YC, Chang CY. Cardiopulmonary resuscitation in prone position: a simplified method for outpatients. J Chin Med Assoc. 2006;69(5):202-206.

50. Mazer SP, Weisfeldt M, Bai D, et al. Reverse CPR: a pilot study of CPR in the prone position. Resuscitation. 2003;57(3):279-285.

51. Hegde S. Which type of personal protective equipment (PPE) and which method of donning or doffing PPE carries the least risk of infection for healthcare workers? Evid Based Dent. 2020;21(2):74-76.

52. Ng QX, De Deyn M, Lim DY, Chan HW, Yeo WS. The wounded healer: A narrative review of the mental health effects of the COVID-19 pandemic on healthcare workers. Asian J Psychiatr. 2020;54:102258. 